\title{
Pleural plaques and asbestosis: dose- and time-response relationships based on HRCT data
}

\author{
C. Paris*\#, S. Thierry*, P. Brochard", M. Letourneux ${ }^{+}$, E. Schorle ${ }^{\S}$, A. Stoufflet*, \\ J. Ameille ${ }^{f}$, F. Conso**, J.C. Pairon ${ }^{\# \#,{ }^{*} \text { and the National APEXS Members }}{ }^{++}$
}

ABSTRACT: Most studies on asbestos-related diseases are based on chest radiographs, and dose-response relationships are still controversial. The aim of this study was to describe the most relevant parameters of asbestos exposure linked to pleural plaques and asbestosis diagnosed by high-resolution computed tomography (HRCT).

A large screening programme including systematic HRCT examinations was organised from 2003 to 2005 in France for formerly asbestos-exposed workers. The time since first exposure (TSFE), level, duration and cumulative exposure to asbestos were used in adjusted unconditional logistic regression to model the relationships of the two diseases.

Analysis of a population of 5,545 subjects demonstrated that TSFE $(p<0.0001)$ and cumulative exposure $(p=0.02)$ (or level, depending on the models used), were independently associated with the frequency of pleural plaques. Only cumulative exposure $(p<0.0001)$ or level of exposure $(p=0.02)$ were significantly associated with asbestosis. All trend tests were significant for these parameters.

To date and to our knowledge, this study is the largest programme based on HRCT for the screening of asbestos-exposed subjects. Both time-response and dose-response relationships were demonstrated for pleural plaques, while only dose-response relationships were demonstrated for asbestosis. These parameters must be included in the definition of high-risk populations for HRCT-based screening programmes.

KEYWORDS: Asbestosis, dose-response, high-resolution computed tomography, pleural plaques, time-response

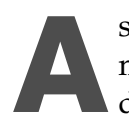
sbestos exposure can lead to the development of benign and malignant respiratory diseases. The commonest asbestos-related diseases are benign diseases and many studies have examined the relationships between asbestos exposure and these diseases [1]. Overall, the prevalence of both pleural plaques and asbestosis is associated with time since first exposure (TSFE) to asbestos, intensity level, duration or cumulative exposure to asbestos depending on the studies [1-4], but these criteria remain poorly defined. Certain differences have been suggested between these two diseases, as TSFE seems to be the best predictor for pleural plaques whereas cumulative exposure was reported to be the major determinant for asbestosis [1, 2]. Moreover, chest radiograph (CXR) features of asbestosis have repeatedly been shown to be associated with heavy asbestos exposure, with a cut-off close to 25 fibres $\cdot \mathrm{mL}^{-1} \cdot \mathrm{yr}^{-1}$ [1].
However, the majority of published studies are based on CXR data, resulting in difficulties for estimation of dose-response relationships for asbestos-related diseases due to imprecise assessment of asbestos exposure but also imprecise radiographic diagnosis of asbestosis and pleural plaques [3]. Thoracic high-resolution computed tomography (HRCT) has been clearly demonstrated to be more sensitive and specific than CXR for the diagnosis of asbestos-related diseases [5]. To our knowledge, only four studies have used HRCT for the assessment of dose-response relationships for pleural plaques and asbestosis [6-9]. Due to various study-dependent conditions, these studies did not provide evidence of clear relationships between asbestosis and pleural plaques and asbestos exposure. In 2001, BÉGIN and CHRISTMAN [10] highlighted the need for an objective and independent measurement of disease activity, such as HRCT, but emphasised
AFFILIATIONS

*INSERM U954, Vandoeuvre-lesNancy,

"Nancy University, Nancy,

"LSTE, Dept of Occupational

Diseases, University Hospital,

Bordeaux,

${ }^{+}$Dept of Occupational Diseases,

University Hospital, Caen,

${ }^{\S}$ ERSM Rhone-Alpes, Regional

Security Insurance, Lyon,

${ }^{f}$ Dept of Occupational Diseases, AP-

HP, Raymond Poincaré Hospital,

Garches,

**IIMTPIF, Paris,

\#\#INSERM U955, Creteil,

"Dept of Occupational Diseases,

Centre Hospitalier Intercommunal, Creteil, France.

${ }^{+}$For full details of the National

APEXS Members, see

Acknowledgements.

CORRESPONDENCE

C. Paris

U954 (ex INSERM ERI no. 11)

Medical School

9 av de la Forêt de Haye - BP 184

54505 Vandoeuvre-les-Nancy Cedex

France

E-mail: christophe.paris@

nancy.inserm.tr

Received:

June 202008

Accepted after revision:

Nov 172008

First published online:

Jan 072009

European Respiratory Journa

Print ISSN 0903-1936

Online ISSN 1399-3003 
that computed tomography (CT) scanning was not yet a "gold standard", despite its higher sensitivity compared with CXR, due to the absence of clearly established exposure-response relationships.

The aim of the present study was to describe the relationships between asbestos exposure and pleural plaques and asbestosis in a large cohort of formerly asbestos-exposed workers, and to assess asbestos exposure parameters linked to the presence of HRCT features of these two diseases by means of multivariate analysis.

\section{METHODS}

\section{Study design}

A large-scale screening programme for asbestos-related diseases, namely the Asbestos Post EXposure Survey (APEXS), was organised at the request of the French Ministry of Labour between October 2003 and December 2005 in four regions of France (Aquitaine, Rhône-Alpes, Lower Normandy and Upper Normandy). The study was initiated following a national consensus statement published in 1999 that recommended the use of chest CT scan for the surveillance of workers with previous moderate-to-high occupational exposure to asbestos [11]. It is noteworthy that, in France, workers are entitled to financial compensation and early retirement in the case of asbestos-related disease, including pleural plaques. The target group for this screening programme comprised unemployed or retired asbestos-exposed workers covered by French National Health Insurance. Various recruitment procedures (letters, newspapers, radio, etc.) were used in each region.

All subjects with supposed occupational asbestos exposure were invited to undergo a free screening programme. The screening programme included physical examination, pulmonary function tests performed by the respiratory physician of the subject's choice and spiral HRCT performed by a programme-approved radiologist. Medical data and a CDROM copy of the HRCT were sent directly to the investigators by the patient's practitioner or radiologist. All data were then rated and recorded in a coordination centre for each region.

\section{Exposure assessment procedures}

Volunteers for the screening programme had to fill out a standardised questionnaire describing all jobs held throughout the subject's working life as well as specific asbestos-exposing tasks. The questionnaires were analysed, blinded to radiological data, by industrial hygienists in Aquitaine and Normandy and by trained national health insurance agents in RhôneAlpes. Asbestos exposure was assessed using an a priori simplified job-exposure matrix according to occupation and industrial activities. The level of exposure was defined for each subject's entire career and classified into four classes: high (defined as continuous exposure for at least $1 \mathrm{yr}$ or discontinuous exposure for at least $10 \mathrm{yrs}$ ), low (passive exposure), moderate (all other occupational exposure) and nil (no exposure). A cumulative exposure index (CEI) was then calculated by multiplying this level $(3,2,1$ and 0 , respectively) by the total exposure duration (in years).

\section{Radiological procedures}

Recommended HRCT acquisition parameters were defined in accordance with the French Thoracic Imaging Society guidelines. The main recommendations were slices with a thickness of $1.5-5 \mathrm{~mm}$, a pitch of $1.5-2.0,120 \mathrm{kV}, 60-150 \mathrm{~mA}$ maximum, window width of $1600 \mathrm{HU}$ and window level of $600 \mathrm{HU}$ for parenchymal slices, window width of $400 \mathrm{HU}$ and window level of $50 \mathrm{HU}$ for mediastinal slices, with differences depending on mono- or multi-detector equipment. Acquisition in the prone position was only required in the case of gravitational abnormalities. All CT scans were performed without contrast material.

Radiologists who participated in the programme (nearly 300) had to sign an agreement statement. They received guidelines to perform HRCT for the diagnosis of asbestos-related benign diseases. Pleural plaques were defined as focal areas of pleural thickening with soft tissue attenuation, which could contain calcification, typically located on the posterior wall of the lower half of the pleural spaces, often in the paravertebral regions, on the anterior wall between the third and the fifth costal interspaces, and/or on the diaphragmatic pleura. Their parietal nature was defined by their sharply defined edge, well demarcated from adjacent lung, usually with a typical tableland shape, easily recognised regardless of their thickness, or sometimes with less typical tapered margins. In the case of atypical pleural features, only bilateral pleural changes, located in typical areas, were taken into account. They had to be differentiated from the transversus thoracis muscle in anterior parasternal areas, and from subcostalis muscles along the posterior chest wall.

Diffuse pleural thickening was not defined by dimensional criteria but by the presence of parenchymal bands and/or rounded atelectasis, showing the visceral nature of the pleural changes.

Asbestosis was defined by the following pulmonary interstitial abnormalities initially affecting subpleural posterobasal pulmonary areas: early subpleural dot-like opacities, intralobular reticulation, subpleural curvilinear line, interlobular septal thickening and ground-glass opacity (the most common findings); and honeycombing (in the case of advanced asbestosis). These features had to affect both lungs and had to remain present on prone views to establish the diagnosis of asbestosis.

Radiologists also received specific training in the interpretation of HRCT from experienced radiologists and occupational physicians.

HRCT reports and films were both sent to coordination centres. For the purposes of the present study, the presence or absence of radiological abnormalities was rated by only using the HRCT reports according to the above definitions by physicians blinded to clinical data.

The project was approved by the Cochin Hospital ethics committee in Paris. All patients received information on the study and gave their written informed consent to the radiologist for the increased radiation dose delivered by HRCT.

\section{Statistical analysis}

The variables used to characterise asbestos exposure were duration of exposure, TSFE, level of exposure and CEI. All variables apart from level of exposure were ranked in classes 
following the quartile distribution of values. The level of exposure was ranked in four classes (nil, low, moderate and high).

Statistical associations between determinants of asbestos exposure and the presence of pleural plaques or asbestosis on HRCT were studied using stepwise unconditional logistic regression. As CEI was a combination of level and duration of exposure, two distinct models were used with either CEI or the other variables (i.e. level and duration of exposure).

\section{TABLE 1}

Age, smoking status, body mass index and main occupational status ${ }^{\#}$ in the Asbestos Post EXposure Survey

\begin{tabular}{|c|c|}
\hline \multicolumn{2}{|l|}{ Age } \\
\hline$<60$ yrs & $1175(21.2)$ \\
\hline $60-75$ yrs & $4163(75.1)$ \\
\hline$\geqslant 75 \mathrm{yrs}$ & $207(3.7)$ \\
\hline Overall" & 5545 \\
\hline \multicolumn{2}{|l|}{ Smoking status } \\
\hline Nonsmokers & $1376(36.5)$ \\
\hline Former smokers & $2066(54.8)$ \\
\hline Smokers & $327(8.7)$ \\
\hline Unknown & 1776 \\
\hline \multicolumn{2}{|l|}{ Body mass index } \\
\hline Underweight & $15(0.4)$ \\
\hline Normal weight & $956(26.2)$ \\
\hline Overweight & $1895(51.9)$ \\
\hline Obese & $787(21.5)$ \\
\hline Unknown & 1892 \\
\hline Overall $^{+}$ & 3653 \\
\hline \multicolumn{2}{|l|}{ Main jobs } \\
\hline $\begin{array}{l}\text { Agricultural- or industrial-machinery mechanics } \\
\text { and fitters }\end{array}$ & $581(10.8)$ \\
\hline Plumbers and pipe fitters & $400(7.4)$ \\
\hline Motor-vehicle mechanics and fitters & $376(7.0)$ \\
\hline Bricklayers and stonemasons & $347(6.4)$ \\
\hline Building and related electricians & $331(6.1)$ \\
\hline Sheet-metal workers & $239(4.4)$ \\
\hline Welders and flame cutters & $228(4.2)$ \\
\hline Metal smelters, casters and rolling-mill operators & $218(4.0)$ \\
\hline Freight handlers & 211 (3.9) \\
\hline Insulation workers & $136(2.5)$ \\
\hline \multicolumn{2}{|l|}{ Main industrial activities } \\
\hline Basic iron and steel manufacture & $488(9.0)$ \\
\hline Complete building construction work & $384(7.1)$ \\
\hline Motor vehicle maintenance and repairs & $320(5.9)$ \\
\hline Metalworking: boilermaking & $268(5.0)$ \\
\hline $\begin{array}{l}\text { Installation of heating and air conditioning } \\
\text { equipment }\end{array}$ & $192(3.6)$ \\
\hline Installation of electrical wiring and fittings & $174(3.2)$ \\
\hline Cargo handling & $172(3.2)$ \\
\hline Iron casting & $165(3.1)$ \\
\hline Electricity production & $143(2.6)$ \\
\hline Ship building and repairs & $139(2.6)$ \\
\hline
\end{tabular}

Data are presented as $\mathrm{n}(\%)$ or $\mathrm{n} .{ }^{*}$ : defined as the job or industrial activities held longest by the subjects; ${ }^{\circ}$ : mean \pm SD $63.5 \pm 5.7$; $^{+}$: mean \pm SD $27.4 \pm 3.8$.
In view of the low prevalence of diffuse pleural thickening, this disease was not specifically analysed, but these patients were included in all analyses concerning pleural plaques and asbestosis.

Crude odds ratios (ORs) and adjusted ORs for confounding factors (body mass index (BMI) and smoking status) were obtained separately for pleural plaques and asbestosis. Trend tests for logistic regressions were obtained using categorical variables as quantitative variables and by replacing ordinal variables by median values.

A cross-validation of a random sample of occupational questionnaires $(n=400)$ and HRCT reports $(n=200)$ was organised in the four regions, yielding agreements between hygienists or physicians rated as good to excellent by $\kappa$ statistics.

All statistical analyses were performed with SAS Software version 9.1 (SAS Institute, Inc., Cary, NC, USA).

\section{RESULTS}

\section{Cohort selection}

A total of 20,157 subjects volunteered to participate in the APEXS and 16,885 subjects returned the completed occupational questionnaire; $13,859(82.1 \%)$ of these subjects were eligible for the screening programme in terms of their National Health Insurance cover and more than half of them $(7,275$; $52.5 \%$ ) underwent thoracic HRCT. Subjects whose HRCT reports were not sent to the coordination centre $(n=734)$ or who presented incomplete data $(n=709)$, as well as females

\section{TABLE 2 Asbestos exposure parameters in the Asbestos Post EXposure Survey}

\begin{tabular}{lccc} 
& $\mathbf{n}(\%)$ & Range & Mean \pm SD \\
\hline Time since first exposure yrs & & & \\
1st quartile & $1355(24.5)$ & $0-37$ & \\
2nd quartile & $1116(20.1)$ & $37-42$ & \\
3rd quartile & $1675(30.2)$ & $42-48$ & \\
4th quartile & $1399(25.2)$ & $48-72$ & \\
Overall & 5545 & & $41.9 \pm 8.1$ \\
Exposure duration yrs & & & \\
1st quartile & $1321(23.8)$ & $0-20$ & \\
2nd quartile & $1324(23.9)$ & $20-29$ & \\
3rd quartile & $1408(25.4)$ & $29-36$ & \\
4th quartile & $1492(26.9)$ & $36-50$ & \\
Overall & 5545 & & $27.4 \pm 11.1$ \\
Level of exposure & & & \\
Low & $166(3.0)$ & & \\
Moderate & $936(16.9)$ & & \\
High & $4443(80.1)$ & & \\
Overall & 5545 & & \\
Cumulative exposure index & & & \\
1st quartile & $1306(23.5)$ & $0-30$ & \\
2nd quartile & $1386(25.0)$ & $30-52$ & \\
3rd quartile & $1380(24.9)$ & $52-70$ & \\
4th quartile & $1473(26.6)$ & $70-100$ & \\
Overall & 5545 & & $49.6 \pm 26.7$ \\
\hline
\end{tabular}


TABLE 3 Prevalence of pleural plaques and asbestosis by age, smoking status, body mass index and main occupational status ${ }^{\#}$ in the Asbestos Post EXposure Survey"

\begin{tabular}{|c|c|c|c|c|c|c|c|}
\hline & \multirow[t]{2}{*}{ Subjects $n$} & \multicolumn{3}{|c|}{ Pleural plaques } & \multicolumn{3}{|c|}{ Asbestosis } \\
\hline & & n (\%) & Mean \pm SD & p-value & n (\%) & Mean \pm SD & p-value \\
\hline \multicolumn{8}{|l|}{ Age } \\
\hline$<60 \mathrm{yrs}$ & & 148 (12.6) & & & $74(6.3)$ & & \\
\hline $60-75$ yrs & & $661(15.9)$ & & & $271(6.5)$ & & \\
\hline \multicolumn{8}{|l|}{ Smoking status } \\
\hline Nonsmokers & & $199(14.5)$ & & & $80(5.8)$ & & \\
\hline Former smokers & & $360(17.4)$ & & & $150(7.3)$ & & \\
\hline Smokers & & $54(16.5)$ & & 0.07 & $30(9.2)$ & & 0.06 \\
\hline Unknown & & $269(15.2)$ & & & $115(6.5)$ & & \\
\hline \multicolumn{8}{|l|}{ Body mass index } \\
\hline Unknown & & $269(14.2)$ & & & $120(6.3)$ & & \\
\hline Overall & & 613 & $27.5 \pm 3.9$ & & 255 & $27.3 \pm 4.1$ & \\
\hline \multicolumn{8}{|l|}{ Main jobs } \\
\hline Insulation workers & 136 & $50(36.8)$ & & & $14(10.3)$ & & \\
\hline Freight handlers & 211 & $46(21.8)$ & & & $29(13.7)$ & & \\
\hline Plumbers and pipe fitters & 400 & $82(20.5)$ & & & $28(7.0)$ & & \\
\hline Sheet-metal workers & 239 & $47(19.7)$ & & & $23(9.6)$ & & \\
\hline $\begin{array}{l}\text { Agricultural- or industrial-machinery } \\
\text { mechanics and fitters }\end{array}$ & 581 & $106(18.2)$ & & & $34(5.9)$ & & \\
\hline $\begin{array}{l}\text { Metal smelters, casters and rolling-mill } \\
\text { operators }\end{array}$ & 218 & $35(16.1)$ & & & $15(6.9)$ & & \\
\hline Electricity production & 143 & $31(21.7)$ & & & $14(9.8)$ & & \\
\hline Basic iron and steel manufacture & 488 & $92(18.9)$ & & & $35(7.2)$ & & \\
\hline Metalworking: boilermaking & 268 & $47(17.5)$ & & & $13(4.9)$ & & \\
\hline $\begin{array}{l}\text { Installation of heating and air conditioning } \\
\text { equipment }\end{array}$ & 192 & $29(15.1)$ & & & $9(4.7)$ & & \\
\hline Installation of electrical wiring and fittings & 174 & $20(11.5)$ & & & $7(4.0)$ & & \\
\hline Complete building construction work & 384 & $30(7.8)$ & & & $24(6.3)$ & & \\
\hline Motor vehicle maintenance and repairs & 320 & $25(7.8)$ & & & $15(4.7)$ & & \\
\hline Iron casting & 165 & $12(7.3)$ & & & $3(1.8)$ & & \\
\hline
\end{tabular}

$(n=255)$ and nonexposed subjects $(n=32)$, were excluded from analysis.

\section{Descriptive analysis}

Global characteristics of the APEXS population $(n=5,545)$ are given in table 1 . The mean \pm SD age was $63.5 \pm 5.7 \mathrm{yrs}$ (range $39-85$ yrs). Among the subjects in whom smoking status was known, 55\% $(2,066)$ were former smokers and only 9\% $(327)$ were current smokers. Only $26.2 \%$ (956) of the population had a normal BMI. The main jobs and industrial activities were metal working, construction and repairs.

Table 2 describes the exposure characteristics. Overall, the mean \pm SD TSFE was $41.9 \pm 8.1$ yrs with an average duration of exposure of $27.4 \pm 11.1 \mathrm{yrs}$. $80 \%(4,443)$ of the study population 


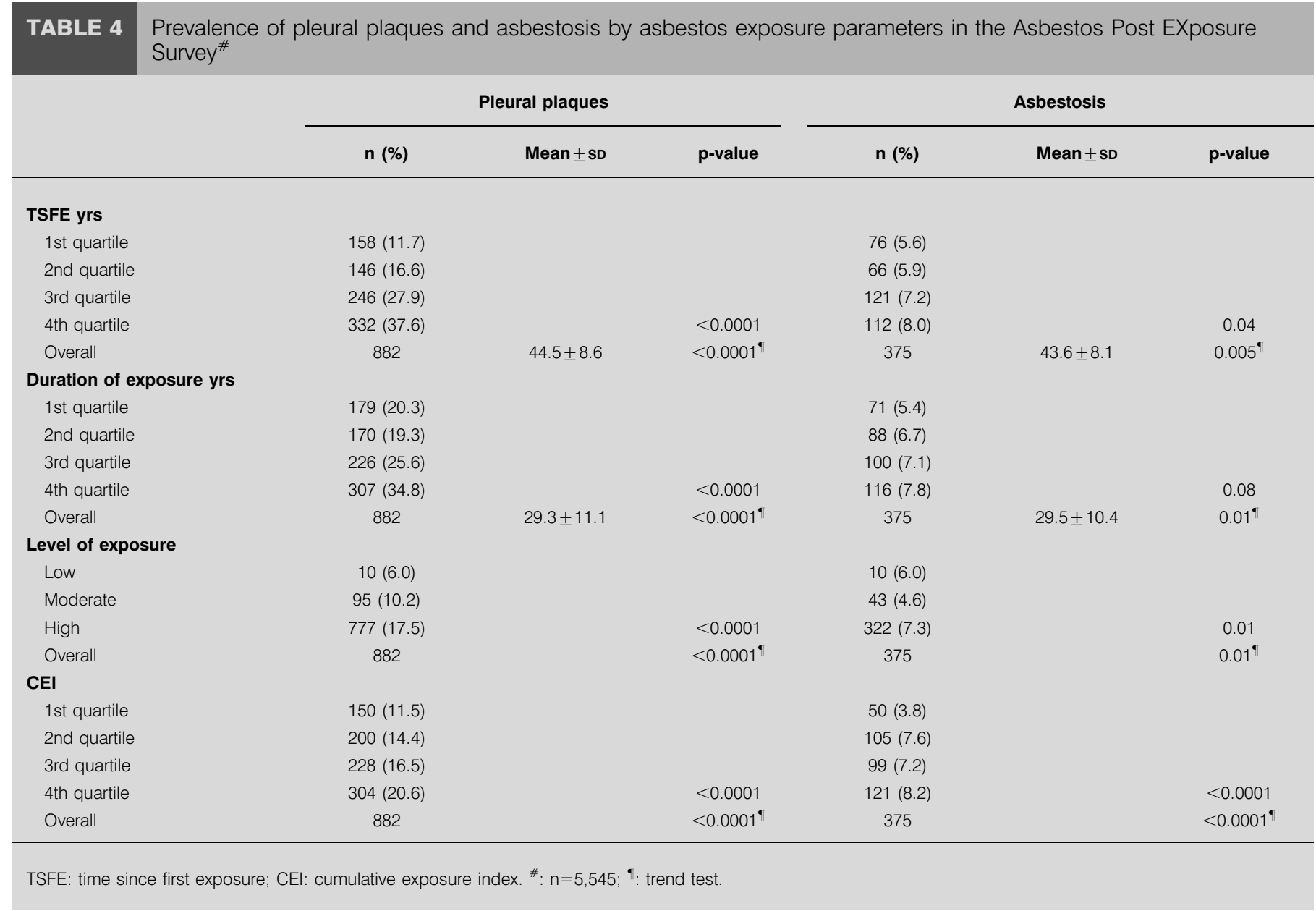

was estimated to have a high level of exposure throughout the entire career.

Based on HRCT data, the overall prevalence was 15.9\% (882 out of 5,545) for pleural plaques, $6.8 \%$ (375) for asbestosis and $0.7 \%$ (37) for diffuse pleural thickening. A significant relationship was observed for both pleural plaques and asbestosis with age and a borderline significant relationship was observed for smoking status (table 3). Higher prevalences of pleural plaques and asbestosis were observed in insulation workers, handlers or shipyard repair workers. Strong relationships were noted for pleural plaques and, to a lesser extent, for asbestosis with the four parameters of asbestos exposure (table 4).

\section{Multivariate analyses: pleural plaques}

On multivariate analyses, all exposure parameters except for duration of exposure showed positive relationships with the prevalence of pleural plaques (table 5). Significant and independent associations were observed between pleural plaques and TSFE and CEI (model I) and between pleural plaques and TSFE and level of exposure (model II). Trend tests were also highly significant for TSFE $(p<0.0001)$, CEI $(p<0.0003)$ and level of asbestos exposure $(\mathrm{p}<0.0001)$. Taking into account the adjustment variables did not modify any of these relationships and had only a minimal effect on ORs.

\section{Asbestosis}

Crude analyses of asbestosis (table 6) showed a positive association with CEI (model I) and TSFE and level of exposure (model II). Only CEI (model I) and level of exposure (model II) remained significant after adjustment for smoking status. However, dose-response curves appeared to be weaker than for pleural plaques.

\section{DISCUSSION}

This large-scale screening programme using HRCT demonstrated strong relationships between asbestos exposure and pleural plaques and, to a lesser extent, between asbestos exposure and asbestosis. Exposure determinants associated with the presence of pleural plaques were both time parameters (TSFE) and dose parameters (CEI or level of exposure depending on the model used). A different pattern was observed for asbestosis, as only dose parameters were significantly associated with the prevalence of this disease. It is noteworthy that no relationship was observed between duration of exposure and these two asbestos-related diseases.

Numerous authors have studied the relationships between asbestos exposure and pleural plaques and the majority have reported the role of TSFE (as latency) in the prevalence of this disease [12-16]. In a recent statement, the American Thoracic Society underlined that TSFE was the parameter most frequently correlated with this disease [1]. For example, 


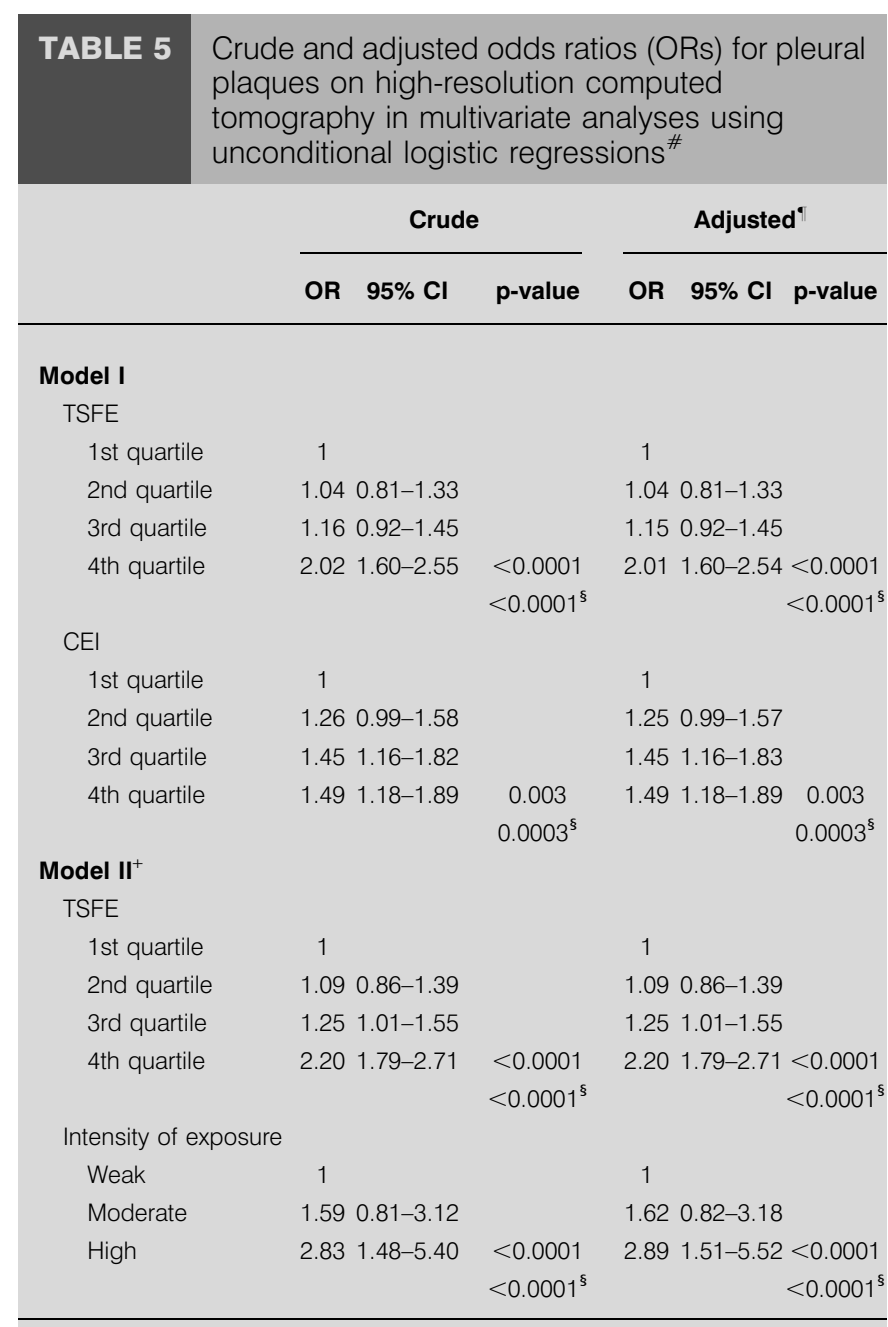

Cl: confidence interval; TSFE: time since first exposure; CEl: cumulative exposure index. ${ }^{\#}: \mathrm{n}=5,545$; $"$ : adjusted for smoking status and body mass index; ${ }^{+}$: TSFE, intensity and duration of exposure were used, but duration of exposure was not significant in the models and was removed; ${ }^{\S}$ : trend test.

KOSKINEN et al. [12], in a large survey of Finnish construction, shipyard and asbestos industry workers, reported a stronger relationship for pleural plaques with TSFE than with duration of exposure. However, multivariate analyses were not performed in this study. In a radiological follow-up of 386 workers exposed to amosite, EHRLICH et al. [14] also found that TSFE was the best predictor of the prevalence of pleural plaques in multivariate analysis, with a significant OR of 1.67 (95\% confidence interval 1.15-2.42) by decade of the variable. JÄRVHOLM [17] consequently included TSFE to model the relationship between asbestos exposure and prevalence of pleural plaques. Conversely, COPES et al. [18], in a study in Quebec chrysotile workers, found that exposure peaks might be the best exposure determinant of pleural plaques. In a multivariate analysis, FINKELSTEIN and VINGILIS [19] suggested that cumulative exposure was the best predictor of pleural plaques. It is noteworthy that all these results are based on CXR. As mentioned in the introductory section, only a few studies using HRCT for the diagnosis of pleural plaques have been published. AlgRANTI et al. [7] found a relationship

\begin{tabular}{|c|c|c|c|c|c|c|}
\hline \multirow[t]{3}{*}{ TABLE 6} & \multicolumn{6}{|c|}{$\begin{array}{l}\text { Crude and adjusted adjusted odds ratios (ORs) } \\
\text { for asbestosis on high-resolution computed } \\
\text { tomography in multivariate analyses using } \\
\text { unconditional logistic regressions }{ }^{\#}\end{array}$} \\
\hline & \multicolumn{3}{|c|}{ Crude } & \multicolumn{3}{|c|}{ Adjusted" } \\
\hline & OR & $95 \% \mathrm{Cl}$ & p-value & OR & $95 \% \mathrm{Cl}$ & p-value \\
\hline \multicolumn{7}{|l|}{ Model I+ } \\
\hline \multicolumn{7}{|l|}{ CEI } \\
\hline 1st quartile & 1 & & & 1 & & \\
\hline 2nd quartile & 2.06 & $1.46-2.91$ & & 2.04 & $1.44-2.88$ & \\
\hline 3rd quartile & 1.94 & $1.37-2.75$ & & 1.93 & $1.36-2.74$ & \\
\hline 4th quartile & 2.25 & $1.60-3.15$ & $\begin{array}{l}<0.0001 \\
<0.0001^{f}\end{array}$ & 2.17 & $1.54-3.05$ & $\begin{array}{l}<0.0001 \\
<0.0001^{f}\end{array}$ \\
\hline \multicolumn{7}{|c|}{ Model II } \\
\hline Weak & 1 & & & 1 & & \\
\hline Moderate & 0.75 & $0.37-1.53$ & & 0.75 & $0.37-1.53$ & \\
\hline High & 1.22 & $0.64-2.33$ & $\begin{array}{l}0.01 \\
0.01^{f}\end{array}$ & 1.20 & $0.62-2.30$ & $\begin{array}{l}0.02 \\
0.02^{f}\end{array}$ \\
\hline $\begin{array}{l}\text { Cl: confidence } \\
\because \text { : adjusted for } \\
\text { were used, but } \\
\text { §: TSFE, intensit } \\
\text { duration of exp } \\
f: \text { trend test. }\end{array}$ & $\begin{array}{l}\text { interval; CE } \\
\text { smoking statu } \\
\text { TSFE was no } \\
\text { ity and duratio } \\
\text { posure were } s\end{array}$ & $\begin{array}{l}\text { El: cumulati } \\
\text { us; }{ }^{+} \text {: time s } \\
\text { ot significan } \\
\text { n of exposu } \\
\text { significant ir }\end{array}$ & $\begin{array}{l}\text { tive expost } \\
\text { since first e } \\
\text { t in the mc } \\
\text { ure were us } \\
\text { in the mod }\end{array}$ & $\begin{array}{l}\text { ure ind } \\
\text { xpposure } \\
\text { odels a } \\
\text { ed, but }\end{array}$ & $\begin{array}{l}\text { dex. } \#: n= \\
\text { re (TSFE) } \\
\text { and was re } \\
\text { it neither TS } \\
\text { nd were re }\end{array}$ & $\begin{array}{l}=5,545 \\
\text { and CEI } \\
\text { emoved; } \\
\text { SFE nor } \\
\text { emoved; }\end{array}$ \\
\hline
\end{tabular}

between TSFE and pleural plaques in 828 former asbestos cement workers, but no multivariate analysis was available in their study. SCHAEFFNER et al. [8], in a series of 102 cases of lung cancer, found a significant relationship between CEI and the simultaneous presence of pleural plaques and asbestosis. VAN CLEEMPUT et al. [9], in a subset of 51 subjects, showed no statistical relationship between cumulative exposure to asbestos or TSFE and the surface area of pleural plaques, as ascertained by HRCT. The present study demonstrates, for the first time, that TSFE and CEI (or level of exposure) are both significantly and independently associated with the prevalence of pleural plaques. These findings partially agree with some of the previous studies discussed and discrepancies with published data may be explained by the statistical power and the use of multivariate analysis in the present study, and by the sensitivity of HRCT compared with CXR for the diagnosis of pleural plaques.

Several studies in which the diagnosis of asbestosis was based on CXR found significant associations between duration of exposure or TSFE and this disease [12, 20, 21], but the strongest associations were generally reported with cumulative exposure $[1,18,19,22]$, by studies including two with multivariate analyses [14, 23]. The study conducted by ALGRANTI et al. [7] using HRCT reported a stronger association between TSFE and asbestosis than between CEI and asbestosis. In a previous and independent study including 706 subjects screened by HRCT [6], it was found that CEI was the best predictor of early asbestosis. The current results are consistent with the hypothesis that cumulative exposure is more important than TSFE for 
the development of asbestosis [4], as no significant relationship was observed for TSFE in adjusted models. These results are in accordance with biological data on retention of asbestos [24]. However, although significant correlations were observed between CEI (or level of exposure) and asbestosis, these correlations appeared to be weak. One explanation for this feature may be the low prevalence of asbestosis observed in this cohort $(6.8 \%)$, which is in agreement with recent data on the time-course of asbestosis epidemiology [25].

This study presents a number of limitations. First, the study population was selected for screening purposes and only volunteers were included. The variety of occupations and industrial activities described in this cohort were similar to those reported in other studies conducted in the general population in France [26]. However, despite the large number of subjects included in this study, the study population may not be representative of the general population.

Secondly, a possibly more important weakness is the procedure used for reading and rating CT scans. In order to validate our results, a random subsample of 1,600 CT scans was independently reviewed by two of the panel of 12 physicians, with a third reading in the case of disagreement. Unilateral pleural plaques were considered relevant only in the case of typical pleural features and, for the diagnosis of pulmonary asbestosis, a bilateral extent of the interstitial abnormalities was needed. This is in accordance with publications dealing with asbestos-related pleural abnormalities and with the weakness of the data about unilateral asbestosis [27, 28]. After review, the same models were confirmed for pleural plaques, but were not significant for asbestosis due to an insufficient number of cases (data not shown). An independent re-interpretation of all CT scans with the same procedure and definitions has since been undertaken and is at present ongoing.

Thirdly, as all asbestos exposure assessments were based exclusively on assessments by industrial hygienists, the accuracy of the parameters used may be questionable, particularly the CEI. Dose-response curves for the prevalence of pleural plaques and asbestosis assessed by HRCT were recently published for a distinct population with available atmospheric measurements [29]. This study corroborated our present findings, albeit the previous study also found a slight but significant association between TSFE and asbestosis prevalence.

A fourth limitation of the study is the presence of numerous missing data, especially for confounding factors such as smoking status or BMI. However, comparisons of subjects with or without these data failed to demonstrate any marked differences between the groups in terms of the distribution of asbestos exposure parameters (data not shown). Moreover, the role of smoking status on parenchymal abnormalities or BMI on pleural plaques appears to predominantly concern results based on CXR analyses [30,31] rather than CT [32].

Finally, as emphasised by STAYNER et al. [23], one of the major limitations of this type of approach to the modelling of exposure is the uncertainty of the models. We used log-linear models to describe the relationship between asbestos-related diseases and exposure. This model is widely used for this purpose in the literature [19] and allows the results to be expressed simply in terms of ORs and numerical classes. However, STAYNER et al. [23] reported that the best predictor model for asbestosis appears to be the power model and JÄRVHOLM [17] also used a similar model to estimate the prevalence of pleural plaques. In accordance with these recommendations, we re-analysed our data using this alternative model and did not observe any differences in terms of significant variables in all models used for either pleural plaques or asbestosis.

\section{Conclusion}

To date, this study is the largest programme based on HRCT for the screening of asbestos-exposed subjects. We report, for the first time, strong and independent correlations between time parameters of asbestos exposure (as expressed by TSFE) and pleural plaques, and between dose parameters (namely cumulative exposure or level of exposure) and both pleural plaques and asbestosis. These findings indicate that these time and dose parameters must be included in the definition of high-risk populations if further screening programmes are considered.

\section{SUPPORT STATEMENT}

This work was supported by grants from the French National Health Insurance (Dept of Occupational Risk Prevention) and the French Ministry of Labour and Social Relations (both Paris, France).

\section{STATEMENT OF INTEREST}

None declared.

\section{ACKNOWLEDGEMENTS}

The members of the APEXS are: J. Ameille (Dept of Occupational Diseases, AP-HP, Raymond Poincaré Hospital, Garches, France), B. Aubert and J.L. Rehel (IRSN, Fontenay-aux-Roses, France), J. Baron, P. Brochard and P. Reungoat (LSTE, Dept of Occupational Diseases, University Hospital, Bordeaux, France), J. Benichou (Dept of Biostatistics, University Hospital, Rouen, France), A. Caillet, N. Lestang, M. Letourneux and M. Pinet (Dept of Occupational Diseases, University Hospital, Caen, France), P. Catilina (Dept of Occupational Diseases, University Hospital, Clermont-Ferrand, France), S. Chamming's and F. Conso (IIMTPIF, Paris, France), G. Christ de Blasi, A. Gislard, M. Maurel, A. Porte and L. Thorel (Dept of Occupational Diseases, University Hospital, Rouen), E. Guichard and E. Schorle (ERSM Rhone-Alpes, Regional Security Insurance, Lyon, France), B. Millet and F.X. Thomas (Dept of Occupational Risk Prevention, Regional Security Insurance, Lyon), L. Mouchot, C. Paris and A. Stoufflet (INSERM U954, Vandoeuvre-lesNancy, France), J.C. Pairon (Dept of Occupational Diseases, Centre Hospitalier Intercommunal, Creteil, France) and A. Sobaszek (Dept of Occupational Diseases, University Hospital, Lille, France). The authors would like to thank all members of the programme for their contribution to this survey.

The authors also thank A. Saul (Paris, France) for his valuable advice in editing this manuscript.

\section{REFERENCES}

1 American Thoracic Society, Diagnosis and initial management of nonmalignant diseases related to asbestos. Am J Respir Crit Care Med 2004; 170: 691-715.

2 Schwartz DA. New developments in asbestos-induced pleural disease. Chest 1991; 99: 191-198. 
3 Boffetta P. Health effects of asbestos exposure in humans: a quantitative assessment. Med Lav 1998; 89: 471-480.

4 Hillerdal G. The human evidence: parenchymal and pleural changes. Ann Occup Hyg 1994; 38: 561-567.

5 Staples CA, Gamsu G, Ray CS, et al. High resolution computed tomography and lung function in asbestos-exposed workers with normal chest radiographs. Am Rev Respir Dis 1989; 139: 1502-1508.

6 Paris C, Benichou J, Raffaelli C, et al. Factors associated with earlystage pulmonary fibrosis as determined by high-resolution computed tomography among persons occupationally exposed to asbestos. Scand J Work Environ Health 2004; 30: 206-214.

7 Algranti E, Mendonça EM, DeCapitani EM, et al. Non-malignant asbestos-related diseases in Brazilian asbestos-cement workers. Am J Ind Med 2001; 40: 240-254.

8 Schaeffner ES, Miller DP, Wain JC, et al. Use of an asbestos exposure score and the presence of pleural and parenchymal abnormalities in a lung cancer case series. Int J Occup Environ Health 2001; 7: 14-18.

9 Van Cleemput J, De Raeve H, Verschakelen JA, et al. Surface of localized pleural plaques quantitated by computed tomography scanning. Am J Respir Crit Care Med 2001; 163: 705-710.

10 Bégin R, Christman JW. Detailed occupational history: the cornerstone in diagnosis of asbestos-related lung disease. Am J Respir Crit Care Med 2001; 163: 598-599.

11 [Consensus development conference for the elaboration of a clinical medical surveillance strategy for people exposed to asbestos. Paris, France, 15 January 1999]. Rev Mal Respir 1999; 16: 1187-1362.

12 Koskinen K, Zitting A, Tossavainen A, et al. Radiographic abnormalities among Finnish construction, shipyard and asbestos industry workers. Scand J Work Environ Health 1998; 24: 109-117.

13 Matrat M, Pairon JC, Paolillo AG, et al. Asbestos exposure and radiological abnormalities among maintenance and custodian workers in buildings with friable asbestos-containing materials. Int Arch Occup Environ Health 2004; 77: 307-312.

14 Ehrlich R, Lilis R, Chan E, et al. Long term radiological effects of short term exposure to amosite asbestos among factory workers. Br J Ind Med 1992; 49: 268-275.

15 de Klerk NH, Musk AW, Williams V, et al. Comparison of measures of exposure to asbestos in former crocidolite workers from Wittenoom Gorge, W. Australia. Am J Ind Med 1996; 30: 579-587.

16 Jakobsson K, Strömberg U, Albin M, et al. Radiological changes in asbestos cement workers. Occup Environ Med 1995; 52: 20-27.

17 Järvholm B. Pleural plaques and exposure to asbestos: a mathematical model. Int J Epidemiol 1992; 21: 1180-1184.
18 Copes R, Thomas D, Becklake MR. Temporal patterns of exposure and nonmalignant pulmonary abnormality in Quebec chrysotile workers. Arch Environ Health 1985; 40: 80-87.

19 Finkelstein MM, Vingilis JJ. Radiographic abnormalities among asbestos-cement workers. An exposure-response study. Am Rev Respir Dis 1984; 129: 17-22.

20 Markowitz SB, Morabia A, Lilis R, et al. Clinical predictors of mortality from asbestosis in the North American Insulator Cohort, 1981 to 1991. Am J Respir Crit Care Med 1997; 156: 101-108.

21 Cookson W, de Klerk N, Musk AW, et al. The natural history of asbestosis in former crocidolite workers of Wittenoom Gorge. Am Rev Respir Dis 1986; 133: 994-998.

22 Jones RN, Diem JE, Hughes JM, et al. Progression of asbestos effects: a prospective longitudinal study of chest radiographs and lung function. Br J Ind Med 1989; 46: 97-105.

23 Stayner L, Smith R, Bailer J, et al. Exposure-response analysis of risk of respiratory disease associated with occupational exposure to chrysotile asbestos. Occup Environ Med 1997; 54: 646-652.

24 Paris C, Galateau-Salle F, Creveuil C, et al. Asbestos bodies in the sputum of asbestos workers: correlation with occupational exposure. Eur Respir J 2002; 20: 1167-1173.

25 Welch LS, Haile E, Dement J, et al. Change in prevalence of asbestos-related disease among sheet metal workers 1986 to 2004 . Chest 2007; 131: 863-869.

26 Goldberg M, Imbernon E, Rolland P, et al. The French National Mesothelioma Surveillance Program. Occup Environ Med 2006; 63: 390-395.

27 Gevenois PA, de Maertelaer V, Madani A, et al. Asbestosis, pleural plaques and diffuse pleural thickening: three distinct benign responses to asbestos exposure. Eur Respir J 1998; 11: 1021-1027.

28 Hosoda Y, Hiraga Y, Sasagawa S. Railways and asbestos in Japan (1928-1987) - epidemiology of pleural plaques, malignancies and pneumoconioses. J Occup Health 2008; 50: 297-307.

29 Paris C, Martin A, Letourneux M, et al. Modelling prevalence and incidence of fibrosis and pleural plaques in asbestos-exposed populations for screening and follow-up: a cross-sectional study. Environ Health 2008; 7: 30.

30 Lee YC, Runnion CK, Pang SC, et al. Increased body mass index is related to apparent circumscribed pleural thickening on plain chest radiographs. Am J Ind Med 2001; 39: 112-116.

31 Delclos GL, Wilson RK, Bradley BL. Influence of smoking on radiographic profusion and pleural changes in asbestos-exposed subjects. J Occup Med 1990; 32: 577-581.

32 Vehmas T, Kivisaari L, Huuskonen MS, et al. Effects of tobacco smoking on findings in chest computed tomography among asbestos-exposed workers. Eur Respir J 2003; 21: 866-871. 